\title{
The englacial stratigraphy of Wilkes Land, East Antarctica, as revealed by internal radio-echo sounding layering, and its relationship with balance velocities
}

\author{
David M. RiPPIN, MartinJ. SIEGERT, Jonathan L. BAMBER \\ Bristol Glaciology Centre, School of Geographical Sciences, University of Bristol, University Road, Bristol BS8 1SS, England \\ E-mail:d.m.rippin@bristol.ac.uk
}

\begin{abstract}
The disruption of internal layering visible in radio-echo sounding (RES) data from East Antarctica has, to date, been attributed to ice flow around bedrock topography. However, observations of internal layer disruption in the Siple Coast ice streams of West Antarctica have led to the suggestion that increased strain at the margins of ice streams may also be responsible for the disruption of internal layers. Here we present a re-analysis of the extensive RES dataset collected between 1967 and 1979 over a large part of Wilkes Land, East Antarctica, and relate the location of continuous and disrupted internal layers to modelled balance velocities. We show that the mean balance velocity associated with all areas of disrupted layers is 2.5 times higher than that associated with areas of continuous layers. We also demonstrate that disrupted layers are associated not only with ice streams, but also with areas of enhanced ice flow, which penetrate inland from the grounding line up to several hundred kilometres into the interior of East Antarctica. Continuous layers always overlie disrupted layers, suggesting either a depth dependency in the process responsible for layer disruption, or subsequent deposition of continuous layers. In some cases, disrupted layers occur outside fast-flow features, and continuous layers occur within fast-flow features. Such regions are explained by short-term flow patterns, but might also be attributed to inaccuracies in the balance-velocity calculations.
\end{abstract}

\section{INTRODUGTION}

Radio-echo sounding (RES) has been used widely for several decades to investigate ice thickness, subglacial topography and subglacial conditions beneath ice sheets and glaciers (see Plewes and Hubbard, 2001, for a review of the use of RES in glaciology). Between 1967 and 1979, approximately 400000 $\mathrm{km}$ worth of airborne RES data were collected over Antarctica in a joint programme involving the Scott Polar Research Institute (SPRI), University of Cambridge, U.K., the U.S. National Science Foundation (NSF) and the Technical University of Denmark (TUD) (e.g. Robin and others, 1977; Drewry, 1983; Siegert, 1999). The data were collected using a $60 \mathrm{MHz}$ radar system, mounted on a U.S. C130 Hercules aircraft, which was flown over the ice sheet in a series of grids with line spacings of $\sim 50 \mathrm{~km}$. An inertial navigation system was used to locate the aircraft, and on long flights over terrain with no ground control the navigational error was thought to be a maximum of $10 \mathrm{~km}$ (personal communication from G. de Q. Robin, 1995). Within this RES dataset, internal layers are common, and are frequently continuous and traceable over long distances (e.g. Siegert, 1999; Hodgkins and others, 2000). Internal layers occur due to electromagnetic reflection from boundaries of dielectric contrast. Reflections may be caused by changes in ice density, variations in acidity due to atmospheric aerosols from volcanic eruptions, or by changes in crystal orientation fabric. However, density variations are unlikely to be the cause of internal reflections at depths greater than $\sim 800 \mathrm{~m}$ (Fujita and others, 1999; Siegert and Fujita, 2001).

Widespread internal layers have been identified across a large part of East and West Antarctica, covered by the SPRI-NSF-TUD surveys (Drewry, 1983). It has been suggested that layers may be classified based on their clarity and continuity, such that clear and continuous layers are restricted to inland regions where the ice has not moved substantially since deposition (Robin and Millar, 1982; Drewry, 1983). Conversely, the disruption and distortion of internal layers was related to the role of particularly rough bed topography (Robin and Millar, 1982; Drewry, 1983). However, recent work on the Siple Coast ice streams of West Antarctica has led to the suggestion that increased strain at the margins of ice streams may also be responsible for the disruption of internal layers, with layers eventually becoming destroyed within ice streams (Jacobel and others, 1993; Bell and others, 1998).

In this paper, we examine RES data from Wilkes Land to map the form of the layer stratigraphy, and determine whether there is a relationship between ice flow and patterns of internal layering. The study region lies within latitudes $66^{\circ} \mathrm{S}$ and $77^{\circ} \mathrm{S}$, and longitudes $120^{\circ} \mathrm{E}$ and $160^{\circ} \mathrm{E}$ (Fig. 1). This area comprises $\sim 1.75 \times 10^{6} \mathrm{~km}^{2}$ and thus incorporates $\sim 13 \%$ of the whole of the East Antarctic ice sheet (EAIS). Of the outlet glaciers which drain this area of East Antarctica, the largest are Ninnis and Mertz Glaciers and the fast-flow feature which lies in the Astrolabe Subglacial Basin.

\section{BALANGE VELOGITIES AND FLOW REGIME}

The traditional view of discharge from an ice sheet is that it is controlled largely by the dynamics of ice streams and outlet glaciers which are separated from inland areas of slow flow 


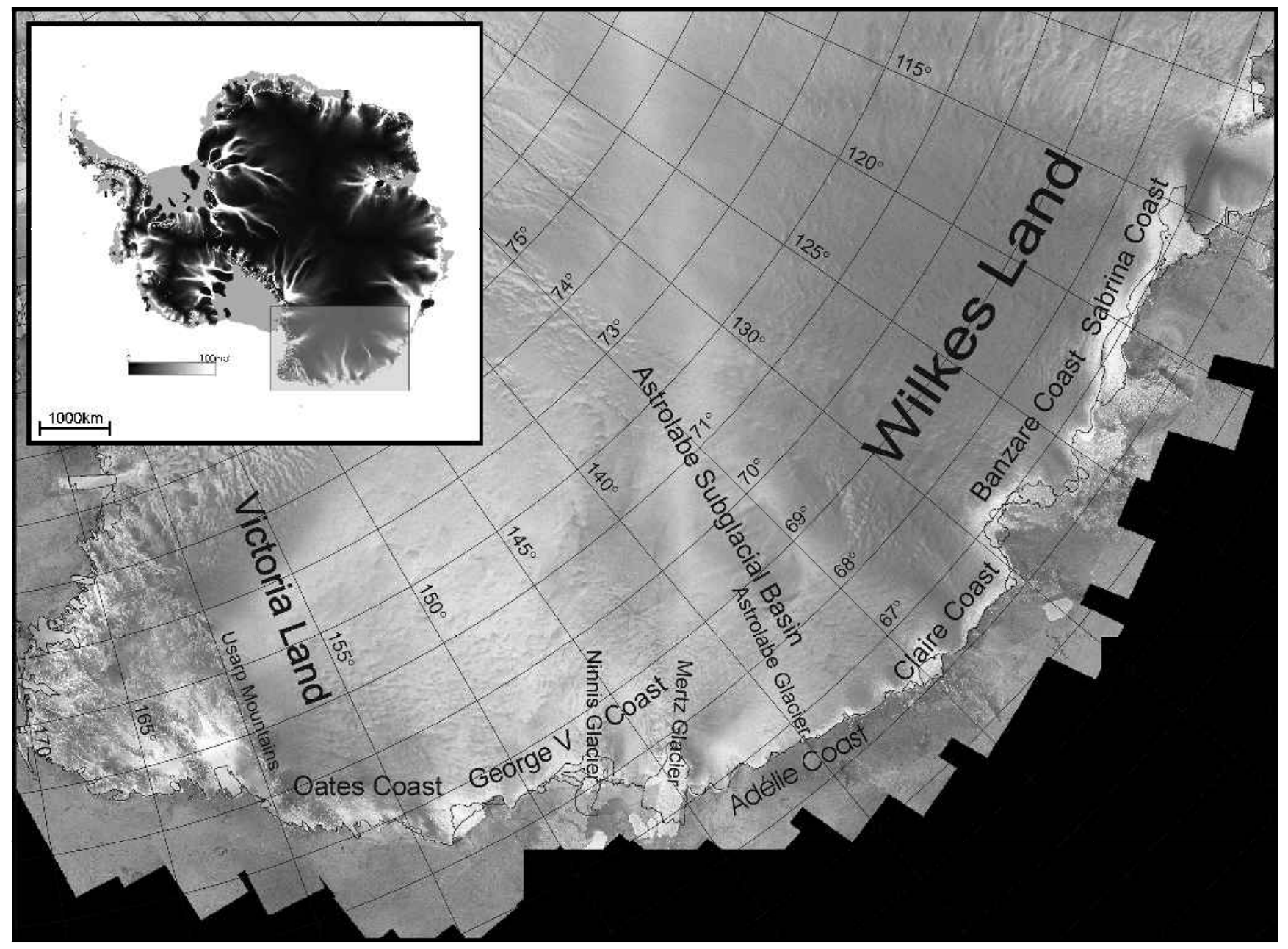

Fig. 1. Map showing the region of Antarctica under investigation, and important place names mentioned in the text. Inset showes balance velocities across the whole of Antarctica, with areas of interest shaded. Map background image is from the RADARSAT Antarctic Mapping Project (RAMP) mosaic of Antarctica (Jezek and others, 2002).

by onset regions and shear margins. Ice experiencing inland or sheet flow moves at a rate of $<30 \mathrm{~m} \mathrm{a}^{-1}$ and is dominated by internal ice deformation (McIntyre, 1985; Bamber and others, 2000b), while active ice streams typically have balance velocities (the velocity required to keep the ice sheet in a state of balance, given a specific net surface mass flux distribution) of the order of $100-2000 \mathrm{~m} \mathrm{a}^{-1}$, and are associated with well-defined shear margins and a decrease in driving stress with increasing ice flux (Bamber and others, 2000b; Bindschadler and others, 2001). Recent work using synthetic aperture radar interferometry (InSAR) in the region of West Antarctica surrounding the Siple Coast ice streams has shown, however, that this traditional view is incomplete and that, in addition, there is a network of tributaries of somewhat enhanced flow which penetrate several hundred kilometres into the ice sheet from the grounding line (Joughin and others, 1999). These tributaries generally have balance velocities of the order of $80-100 \mathrm{~m} \mathrm{a}^{-1}$, and in satellite imagery there are no clearly defined shear margins for much of their length (Bamber and others, 2000b). Recent modelling work using depth-averaged balance velocities as a proxy for the velocity field has shown that flow in the interior of the EAIS may also be more complex than previously thought, and areas of enhanced flow of similar magnitudes to those in the West Antarctic ice sheet (WAIS) also penetrate inland from East Antarctic ice streams and outlet glaciers (Bamber and others, 2000b).

\section{METHODOLOGY}

Analogue RES data, in the form of Z-scope radargrams (which display a series of single electromagnetic returns, collected along track, where the brightness indicates the strength of each reflection) were analyzed qualitatively to determine the configuration of internal layering along several flight tracks. The locations of different types of layering were mapped by using the original flight navigation records.

Three types of internal layering were identified as follows:

(i) well-preserved, continuous internal layers which may be traced for some distance; these layers are often relatively flat, but may also be deformed over underlying subglacial topography; the amplitudes of all undulations are less than those of the bed, and the dominant waveleng ths of the bed and layers are similar;

(ii) disrupted layers, which are clearly disrupted in a manner that does not reflect subglacial topography; the wavelengths of the undulations are shorter than those of the bed, and these disrupted layers are often overlain by continuous layers; and

(iii) a lack of any clear internal layers.

Examples of each type of layer are shown in Figure 2. Although a lack of layering is easy to identify, its cause may or may not be related to glaciological phenomena. For example, a 


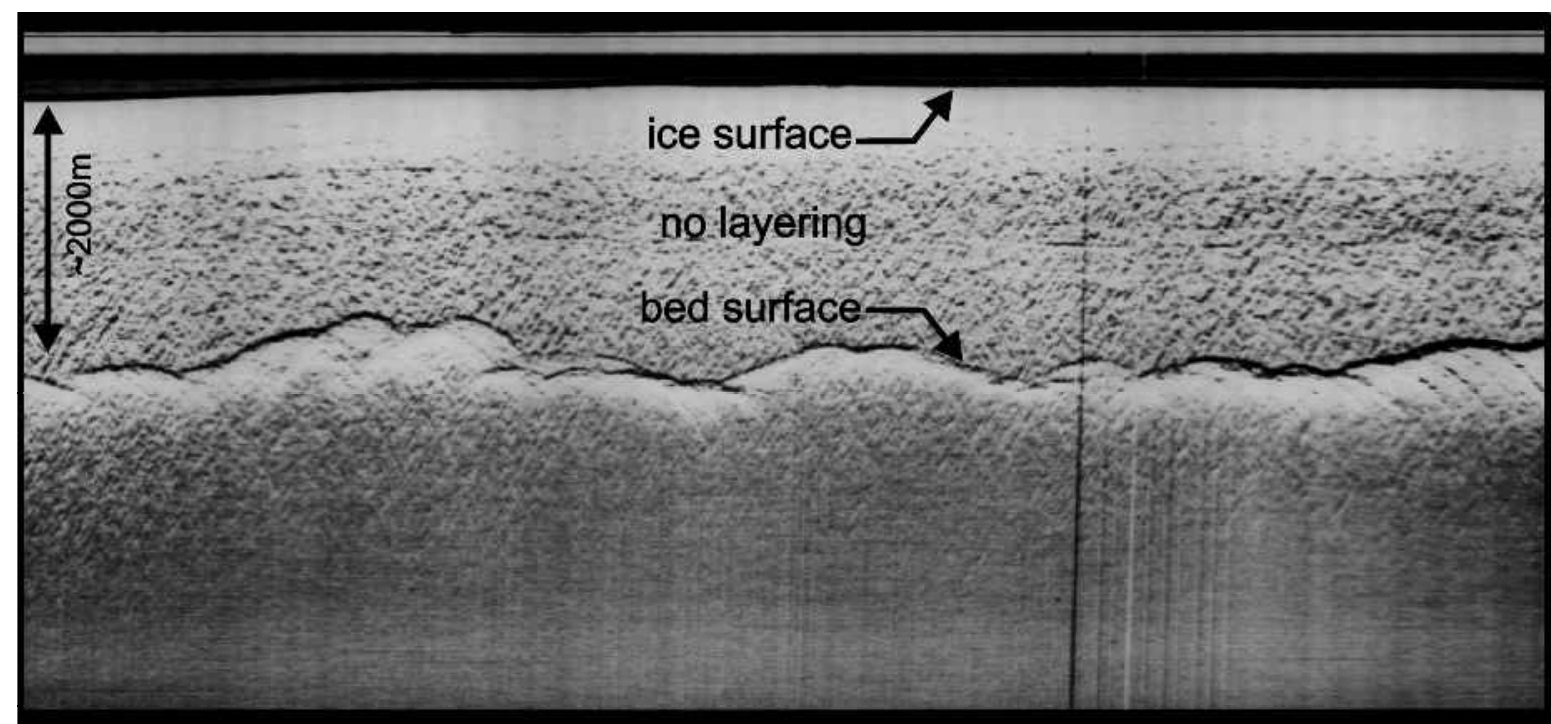

b

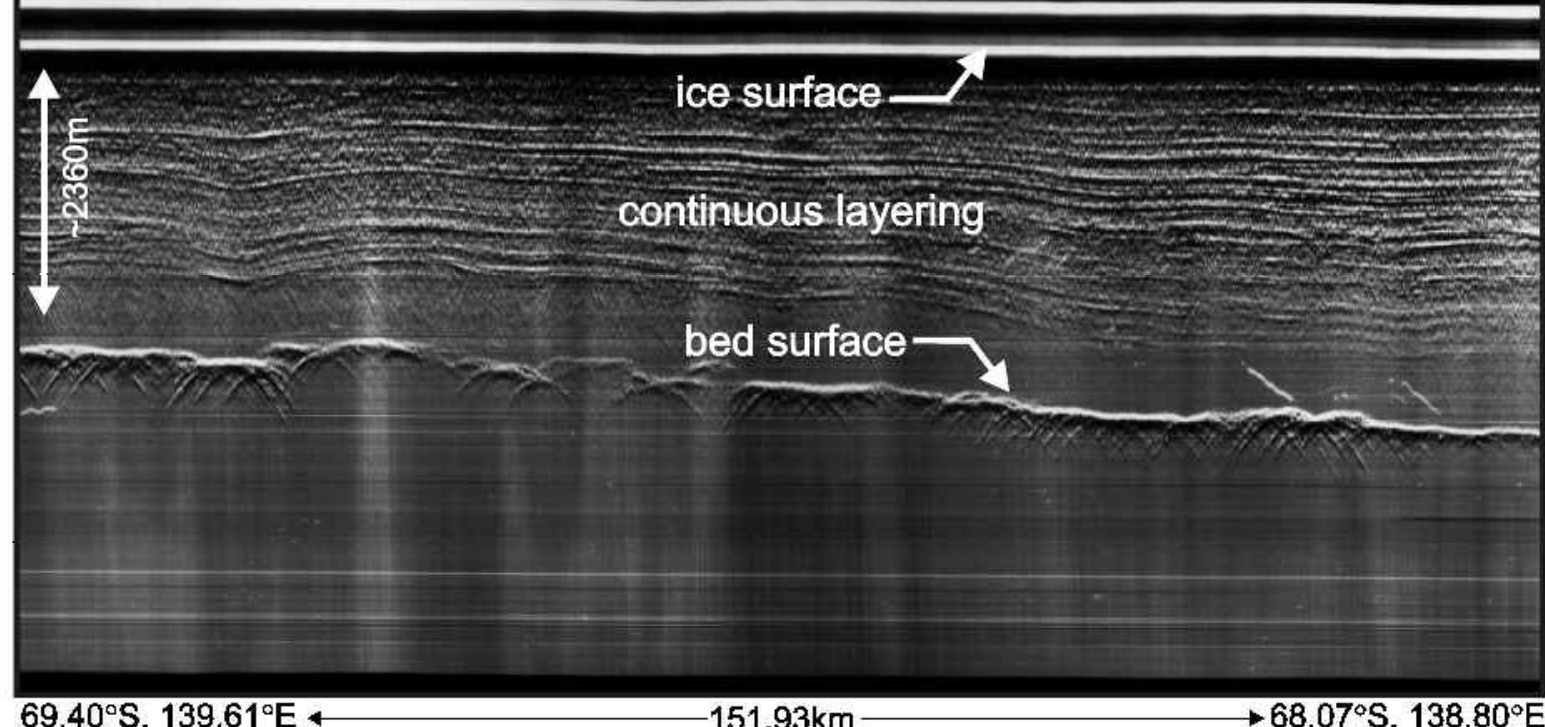

C

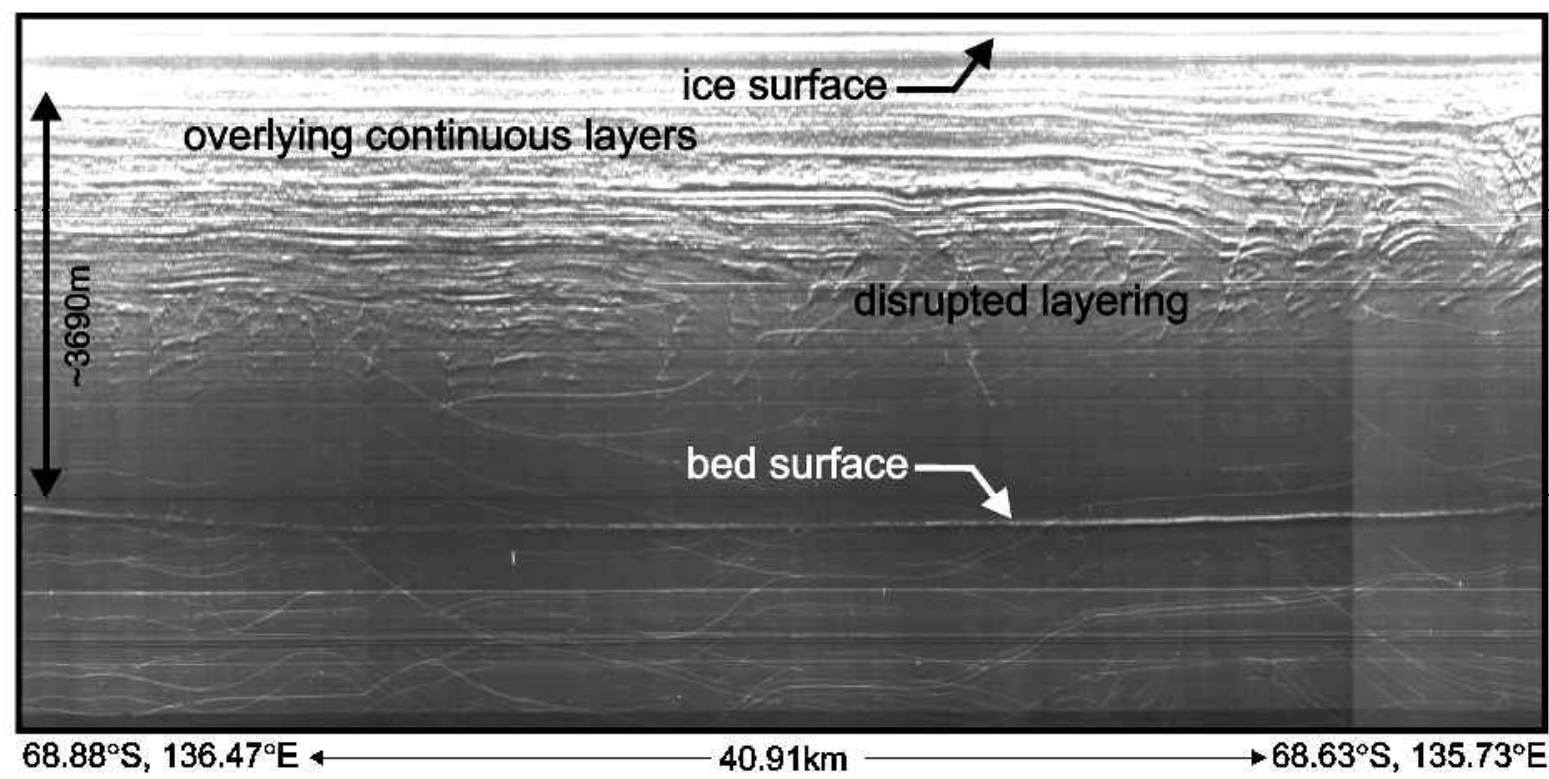

Fig. 2. Examples of: Z-scope RES data, showing: ( a) no internal layering; ( b ) continuous internal layering; ( c) disrupted internal layering, overlain by continuous layers. Distance and depth scales are marked on each image. Flow direction in ( $a$ ) is perpendicular to the profile, into the page; in (b) is perpendicular to the profile, out of the page; and in (c) is perpendicular to the profile, out of the page. The sites from which these examples are taken are shown in Figure 3, and are identified by lower-case a, $b$ and $c$. 


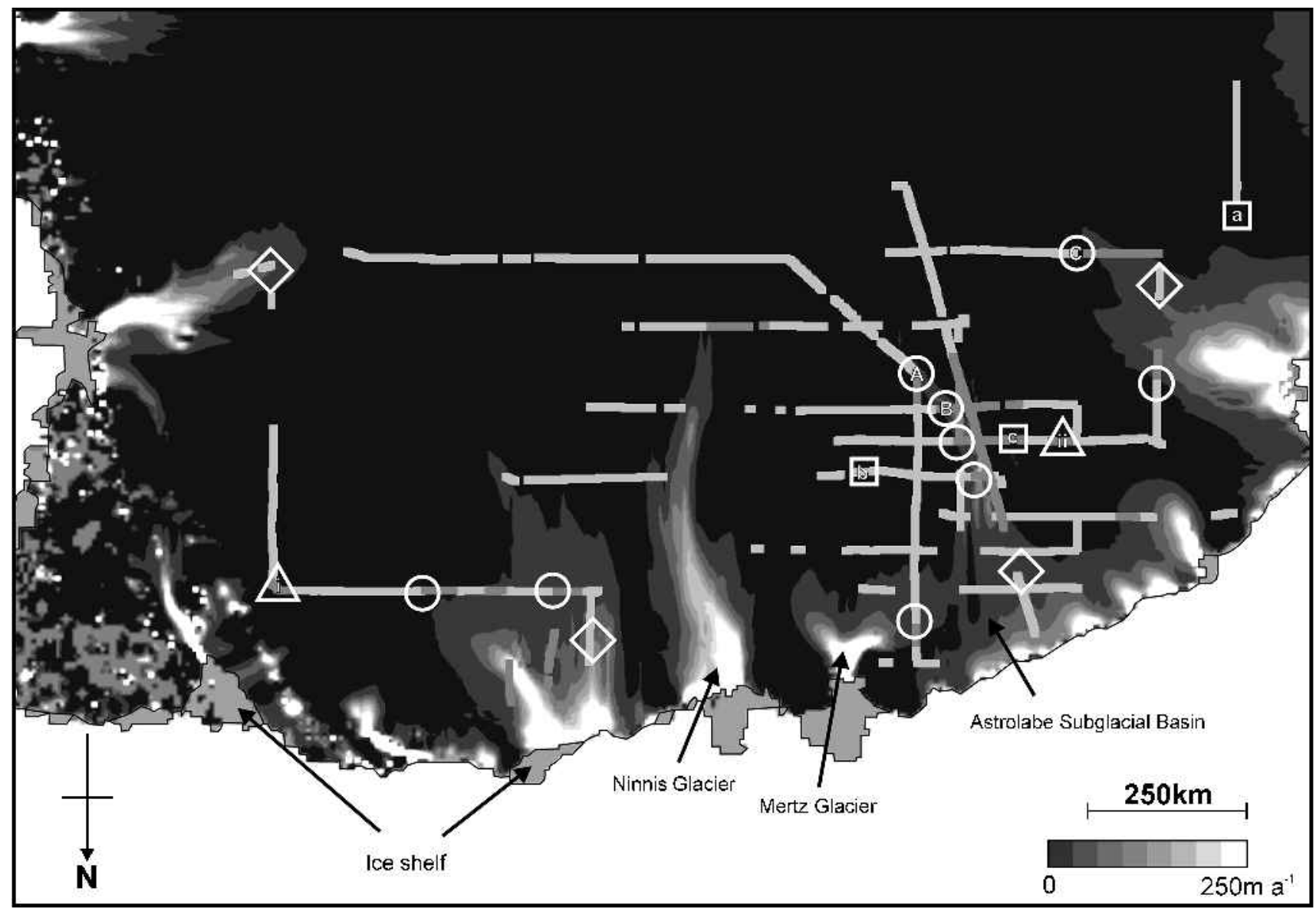

Fig. 3. Depth-averaged balance velocities, and internal layer types. The location of continuous internal layering (light-grey tracks) and disrupted internal layering (dark-grey tracks) is provided. Squares with lower-case letters a, $b$ and $c$ reveal the sites from which the examples in Figure 2 are taken. Circles denote locations where the boundary between continuous and disrupted internal layering is abrupt and also coincides with the boundary between inland flow and fast flow. Upper-case $A, B$ and $C$ indicate the locations of examples shown in Figure 4. Triangles show areas where disrupted layers occur within areas of slow flow. Diamonds show areas where continuous layers occur within regions of fast flow.

lack of clear layering may be a result of a loss of radio-wave power, due to increasing ice thickness and/or increasing aircraft elevation. Consequently, because of this uncertainty, we do not interpret areas where layers are not detected.

Variations in ice thickness and aircraft altitude may also have been responsible for the widely varying clarity of layering in individual RES lines, although most differences are probably caused by the set-up of the analogue recording system. As a result of the variability between traces, it was not possible to use quantitative methods to measure the configuration and reflection strength of internal layers. Consequently, determination of layer type was carried out in a qualitative manner, and no attempt was made to measure or describe the strength or number of internal reflections. The results presented here should be viewed with this in mind. The spatial distribution of layer types was then compared with depth-averaged balance velocities.

Balance velocities for the grounded part of the ice sheet were calculated from three datasets: surface slope, ice thickness and mean net surface mass balance, using a two-dimensional finite-difference scheme (Budd and Warner, 1996; Bamber and others, 2000b). Balance velocities are both depth- and time-averaged. While the dynamic response time of East Antarctica is thought to be of the order of 10000 years, mass-balance data are available over much shorter time-scales (decades). An assumption of the model is therefore that during the response time of the ice sheet the accumulation and ablation rates are relatively constant (Bamber and others, 2000a). In terms of assessing errors in this balance-velocity model, it should be noted that surface slope is the factor most responsible for controlling balance velocities. Surface slope is, however, scaled by mass balance and ice thickness (Bamber and others, 2000b). Surface mass-balance errors are estimated at 10\% (Vaughan and others, 1999). Errors in ice thickness are estimated at an average of $20 \%$, although this is greater in some areas due to substantial regional variations (Bamber and Huybrechts, 1996). These errors have no effect on the pattern of tributary flow, since enhanced-flow areas are at least 100-200\% faster-moving than the surrounding slower regions of the ice sheet, and errors of a similar order would be required for thickness to have an impact on the location of tributaries.

\section{RESULTS}

Balance velocities for the whole of Antarctica are shown in Figure 1, while those for the area of this investigation are shown in Figure 3. The balance-velocity calculations clearly delineate distinct flow units (Bamber and others, 2000a) and accurately predict the location of major glaciers and ice streams within the region of this investigation, including the fast-flow feature in the Astrolabe Subglacial Basin, Mertz and Ninnis Glaciers, as well as a number of other 
a

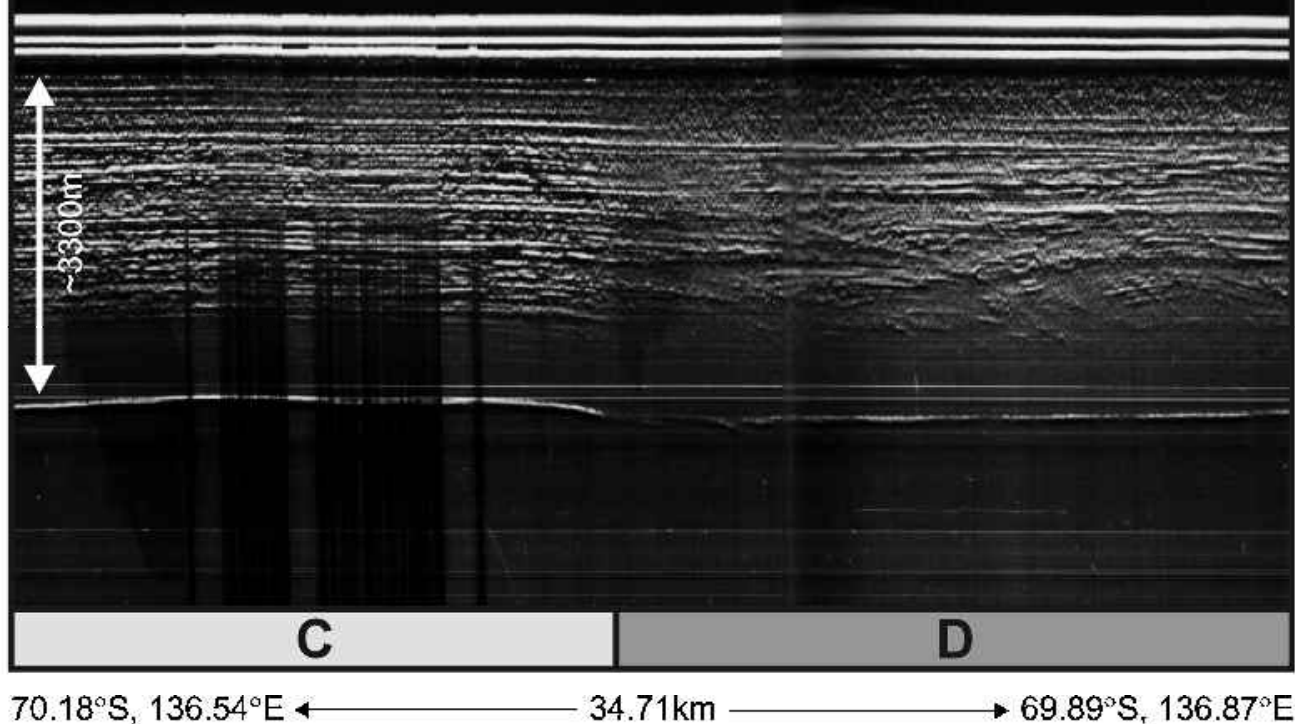

b

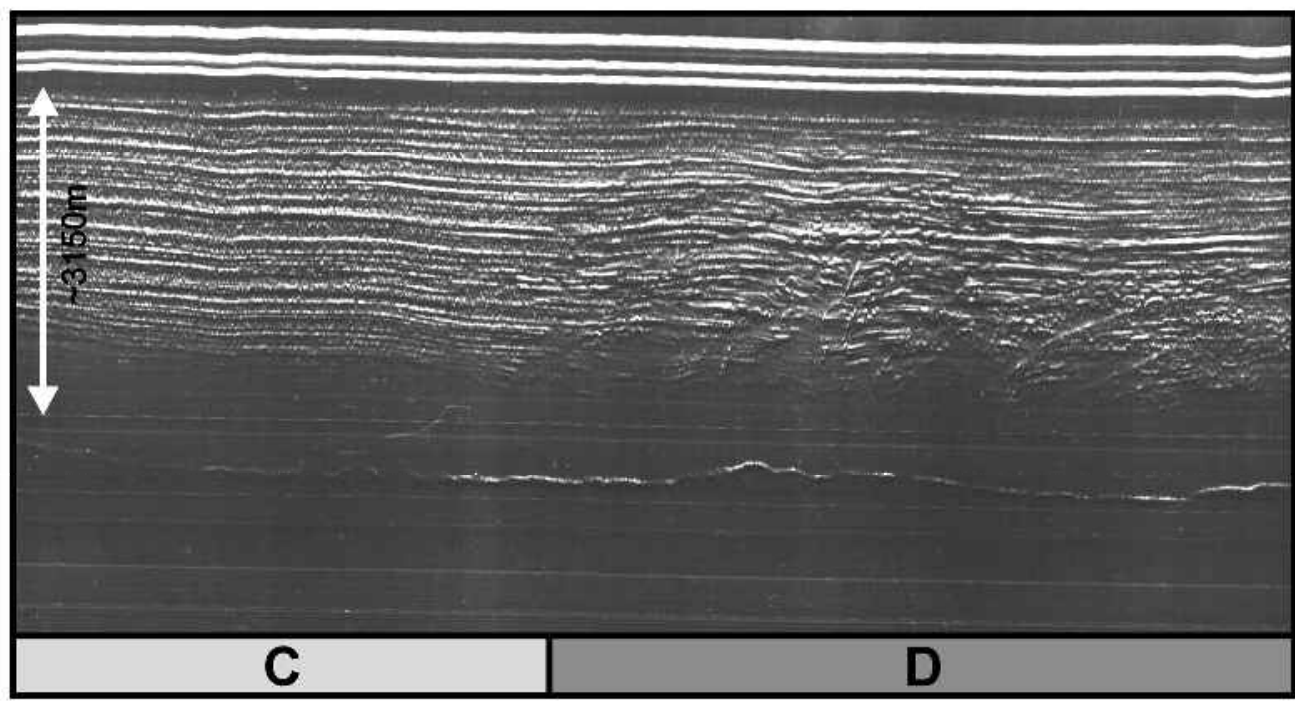

$69.70^{\circ} \mathrm{S}, 137.44^{\circ} \mathrm{E}$

$63.65 \mathrm{~km}$

$69.33^{\circ} \mathrm{S}, 136.20^{\circ} \mathrm{E}$

C

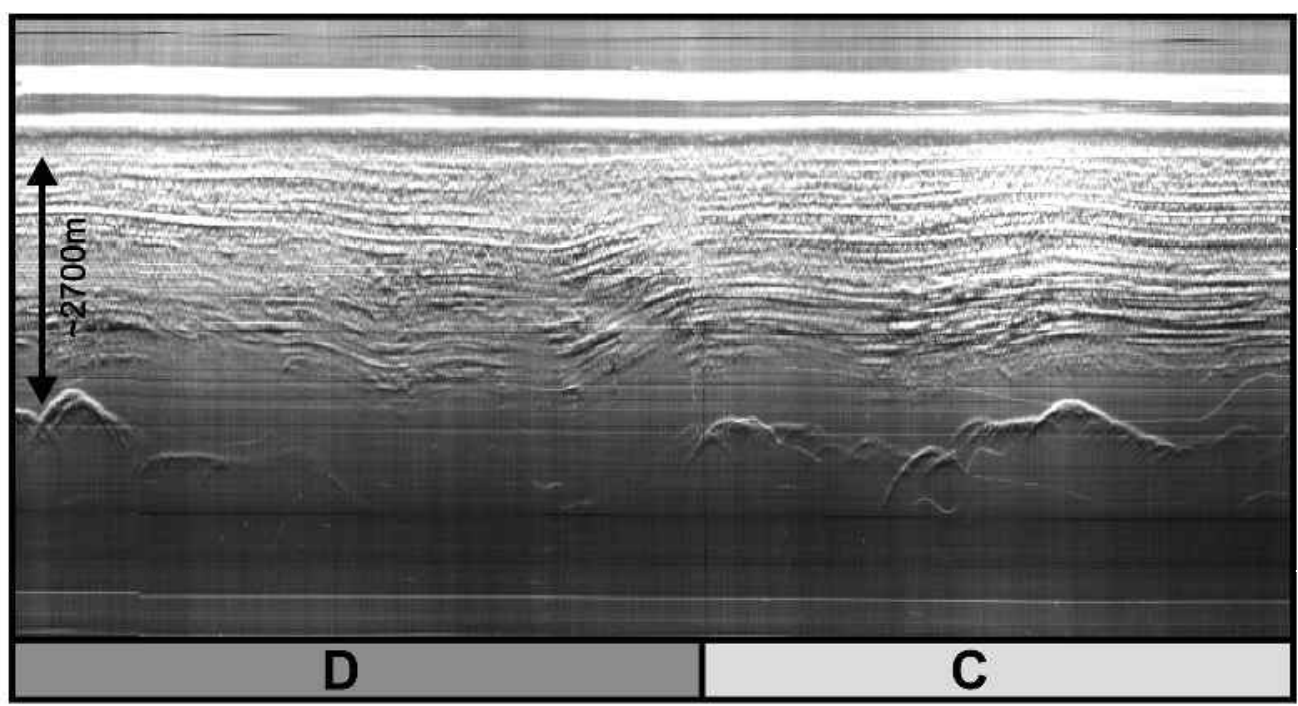

$69.51^{\circ} \mathrm{S}, 129.54^{\circ} \mathrm{E}$

$58.93 \mathrm{~km}$

$\rightarrow 69.92^{\circ} \mathrm{S}, 130.50^{\circ} \mathrm{E}$

Fig. 4. Z-scope images at three sample locations where the boundary between continuous and disrupted internal layering coincides with the boundary between inland and enhanced flow. In each image, the light-grey bar and letter " $C$ " indicates areas where continuous layering is present. The dark-grey bar and letter " $D$ " indicates areas where disrupted layering is present. Distance and depth scales are marked on each image. Flow direction in $(a)$ is towards the right of the image; in $(b)$ is perpendicular to the profile, out of the page; and in (c) is approximately towards the left of the image. The sites from which these examples are taken are shown in Figure 3, and are identified by upper-case A, B and $C$. 
smaller fast-flow features. Significantly, they also show a series of tributaries of moderately fast flow, extending deep into the ice-sheet interior.

Within this region of East Antarctica, there are nearly $8500 \mathrm{~km}$ of airborne radio-echo sounding flight-lines and associated navigation records, available from the SPRINSF-TUD programme. Internal layering is visible along nearly $5800 \mathrm{~km}(\sim 68 \%)$ of the flight-lines, with no layering visible for the remaining $32 \%$. Of the $5800 \mathrm{~km}$ with layering, layers are clear and continuous for $\sim 4850 \mathrm{~km}(84 \%)$, while they are disrupted for the remainder $(\sim 16 \%)$. It is important to note that where disrupted layers are present, they occur at depth and are overlain by continuous layers. The overlying region of continuous layers accounts for 40$60 \%$ (mean $\sim 49 \%$ ) of the total ice thickness, while the disrupted part accounts for $10-40 \%$ (mean $\sim 24 \%$ ) of the total ice thickness. Underlying this, no internal reflections were detected, and this accounts for $15-40 \%$ (mean $\sim 27 \%$ ) of the total ice thickness. Flight-lines are superimposed on Figure 3, and are shaded to show areas of continuous internal layers and disrupted internal layers.

Although continuous internal layers dominate much of the study area, there are a number of areas of disrupted layers, and these disrupted layers exist within, or in close proximity to, fast-flow features, as identified by higher balance velocities (Fig. 3). These areas are:

(i) associated with two small glaciers to the east of Ninnis Glacier in the George V Coast region;

(ii) a region near the head of Ninnis Glacier;

(iii) an area to the west of Mertz Glacier;

(iv) three areas to the west of the Astrolabe Subglacial Basin;

(v) most notably, a large area associated with a fast-moving internal part of the Astrolabe Subglacial Basin (Fig. 3; cf. Fig. 1).

The mean balance velocity in all areas where continuous layers occur is $\sim 17.8 \mathrm{~m} \mathrm{a}^{-1}$, while the mean balance velocity in all areas where disrupted layers occur is $\sim 42.5 \mathrm{~m} \mathrm{a}^{-1}$. Thus, mean flow velocities in areas of disrupted layers are nearly 2.5 times greater than in areas of continuous layers.

Additionally, in a number of locations, there is a distinct transition from continuous to disrupted internal layers, which coincides closely with an acceleration in balance velocity (Fig. 3). Four of these regions lie at the margins of the Astrolabe Subglacial Basin, two are associated with a glacier to the east of Ninnis Glacier, one with a glacier to the west of Mertz Glacier, and two with glaciers to the west of the Astrolabe Subglacial Basin (Fig. 3). Examples of this sharp transition between continuous and disrupted layers, across a region where there is an acceleration in balance velocities, are shown in Figure 4 (cf. Fig. 3).

Despite this general trend, there are some anomalies. There is one area of disrupted layers unrelated to any fastflow feature, located towards the Usarp Mountains, and another to the west of the Astrolabe Subglacial Basin (Fig. 3; cf. Fig. 1). Together, these areas of disrupted layers persist for a distance of $\sim 57 \mathrm{~km}$, and constitute $\sim 6 \%$ of all areas of disrupted layering. Consequently, 94\% of all disrupted layers are associated with areas of increased balance velocities.

In three areas identified in our analysis (to the east of Ninnis Glacier, in the lower part of the Astrolabe Subglacial
Basin, and to the west of the Astrolabe Subglacial Basin), continuous layers exist within fast-flow regions (Fig. 3). Together, these areas constitute $\sim 660 \mathrm{~km}$ of flight-lines ( $\sim 14 \%$ of all continuous layers), with the largest region being in the Astrolabe Subglacial Basin.

\section{DISGUSSION}

The relationship observed here in East Antarctica, between balance velocities and the disruption of internal layers, suggests that the mechanism responsible for increased velocities may also be the cause of the disruption of internal layers. The disruption of internal layers where velocities increase has also been observed in West Antarctica. It has been proposed that such layer disruption may actually characterize streaming flow (Jacobel and others, 2000), or the margins of ice streams, with layers being completely destroyed within ice streams (Jacobel and others, 1993; Bell and others, 1998). Disturbed internal stratigraphy at the margins of Ice Streams C and D was considered an inevitable consequence of the different origins and dynamic histories of ice on either side of the margin (Jacobel and others, 1996). This disruption/destruction of internal layers has been attributed to high longitudinal strains within regions experiencing fast flow and lateral shear strains set up at the boundary between fast- and slow-flowing parts of the ice sheet (Jacobel and others, 1996). The occurrence of significant strain between fast- and slow-moving areas is not debatable, and it is likely that this strain is sufficient to cause the disruption of internal layers.

Significantly, disrupted layers are coincident not only with ice streams, but also with other areas of enhanced flow, which suggests that substantial shear occurs at the margins of these features, even though velocities are lower, and there are apparently no well-defined shear margins in satellite imagery. Variations in the degree of layer disruption would seem to be an inevitable consequence of the varying magnitudes of fast flow, and the resulting strain at the boundaries between ice bodies flowing at different velocities. A spectrum of flow behaviour therefore leads quite understandably to a spectrum of results. It is also possible, however, that basal roughness can still cause the disruption of layers, especially where the location of ice streams is topographically controlled.

However, since all areas of disrupted layering are overlain by significant thicknesses of continuous layers, it is suggested that either the process responsible for the disruption of layers is depth-dependent, or these continuous layers were deposited subsequent to the disrupting process. If continuous layers were deposited after the disrupting process ceased, it suggests that shearing ceased, and that these are relict margins (Jacobel and others, 1996).

In some locations, continuous layers exist within fastflow features (Fig. 3). Two of these locations lie close to the coast (to the east of Ninnis Glacier, and most significantly in the Astrolabe Subglacial Basin), where ice is thinner, while the third (west of the Astrolabe Subglacial Basin) does not (Fig. 3). Such islands of well-preserved layers account for $\sim 14 \%$ of all continuous layers.

Only $6 \%$ of disrupted layers are unrelated to fast-flow features. In one region, towards the Usarp Mountains, disrupted layers occur distant from any fast-flow feature (Fig. 3; cf. Fig. 1), while the other region of anomalous disrupted layers lies in 
relatively close proximity to a region of enhanced flow ( $~ 70 \mathrm{~km}$ west of the Astrolabe Subglacial Basin).

Islands of continuous layers in fast-flow regions may be explained if the processes which lead to the disruption have not been active, or if they occurred at a reduced magnitude (Jacobel and others, 2000). This may be explained if the process is depth-related, and if ice is too thin for the disrupting process to occur. The mean ice thickness where continuous layers occur in fast-flow regions is $1766.72 \mathrm{~m}$, while the mean ice thickness where disrupted layers occur is $2753.20 \mathrm{~m}$. This represents a $56 \%$ difference, and indicates that disrupted layers occur in much thicker ice, and beneath a substantial thickness of ice containing continuous layers.

Another possible explanation is that transient ice-sheet behaviour, not represented by balance velocities, may be responsible for continuous layers in apparent fast-flow regions. Although balance velocities are considered to reflect longterm averages, it is possible that flow paths in the ice-sheet interior may respond quickly to small changes in slope reflecting relatively minor changes in geometry. For example, previous work has discussed the possible migration of the onset regions of West Antarctic ice streams (e.g. Bindschadler, 1997; Price, 1998; Bindschadler and others, 2001). It has been suggested that the mechanism of "episodic migration" (Whillans and others, 1987), in which the onset location jumps from site to site, might be responsible for generating rafts of relatively undisturbed ice in Whillans Ice Stream (formerly Ice Stream B) (Whillans and others, 1987; Bindschadler and others, 1988, 2001). A similar mechanism might also be responsible for the anomalous regions seen in the work presented here.

Apparently anomalous regions of disrupted layers in slow-flow regions may also be explained by migration or shrinkage of fast-flow tributaries, associated with relatively rapid changes in flow paths. The presence of disrupted layers associated with a surface scar feature, distant from the margin of Ice Stream C in the Siple Coast region of West Antarctica, was used as evidence that this was a former icestream margin which had been abandoned (Jacobel and others, 1996, 2000). It is also possible that the disruption of layers in slow-flowing regions may be due to flow across very undulating subglacial topography.

At present, it is not known which of these explanations is correct. However, transient ice-sheet behaviour, as well as possible errors in the balance-velocity map, may be important (Bamber and others, 2000a; Bindschadler and others, 2001).

\section{GONGLUSIONS}

Airborne RES data from East Antarctica were analyzed in order to map out where internal ice-sheet layers are continuous and well preserved, and where they are disrupted. Our qualitative assessment of the internal stratigraphy was superimposed over a map of ice balance velocities (Bamber and others, 2000b). Assuming that the balance fluxes accurately represent relative ice velocities and flow paths, we were able to compare the englacial conditions with regions of fast-flow and slow-flowing ice.

Taking into account all areas of disrupted layers, they are associated with mean balance velocities more than 2.5 times greater than mean balance velocities in areas of continuous layers.

In $88 \%$ of cases, continuous, well-preserved internal layers occur within slow-flowing inland regions of East
Antarctica, while the internal layers become disrupted in fast-flowing ice streams and areas of enhanced flow (fast-flow features).

The widespread occurrence of continuous layers overlying all areas of disrupted layers implies the deposition of overlying layers subsequent to layer disruption, or depth dependency in the processes responsible for layer disruption.

In only $12 \%$ of cases, small areas of disrupted layers lie outside areas of fast-flow, and areas of continuous layers lie within fast-flow, features. These anomalous regions may be explained by the migration of fast-flow features.

This is the first study to map the ice-stratigraphy characteristics in Wilkes Land, and to use balance velocities to explain englacial stratigraphy. The association of continuous layers with slow-flowing regions, and of disrupted layers with fast-flowing regions, is not necessarily surprising. However, the observed relationship implies that long-term patterns of ice flow are sufficient explanation for the disruption of internal layering.

Comparison with previous work suggests that anomalies in the relationship may be due to the migration of fast-flow features. The possible migration of East Antarctic fast-flow features has important implications for ice-sheet evolution (Bindschadler and others, 2001).

\section{ACKNOWLEDGEMENTS}

The research presented here was supported by U.K. Natural Environment Research Council grant GR3/AFI2/65. We are also grateful to the editor, C. Raymond, and two anonymous referees for their comments on the paper.

\section{REFERENCES}

Bamber, J. L. and P. Huybrechts. 1996. Geometric boundary conditions for modelling the velocity field of the Antarctic ice sheet. Ann. Glaciol., 23, 364-373.

Bamber, J. L., R.J. Hardy and I. Joughin. 2000a. An analysis of balance velocities over the Greenland ice sheet and comparison with synthetic aperture radar interferometry. f. Glaciol., 46(152), 67-74.

Bamber, J. L., D. G. Vaughan and I. Joughin. 2000b. Widespread complex flow in the interior of the Antarctic ice sheet. Science, 287(5456), 12481250.

Bell, R. E. and 6 others. 1998. Influence of subglacial geolog y on the onset of a West Antarctic ice stream from aerogeophysical observations. Nature, 394(6688), 58-62.

Bindschadler, R. 1997. Actively surging West Antarctic ice streams and their response characteristics. Ann. Glaciol., 24, 409-414.

Bindschadler, R. A., P. L. Vornberger, S. N. Stephenson, E. P. Roberts, S. Shabtaie and D. R. MacAyeal. 1988. Ice-shelf flow at the boundary of Crary Ice Rise, Antarctica. Ann. Glaciol., 11, 8-13.

Bindschadler, R., J. Bamber and S. Anandakrishnan. 2001. Onset of streaming flow in the Siple Coast region, West Antarctica. In Alley, R. B. and R. A. Bindschadler, eds. The West Antarctic ice sheet: behavior and environment. Washington, DC, American Geophysical Union, 123-136. (Antarctic Research Series 77.)

Budd, W. F. and R. C. Warner. 1996. A computer scheme for rapid calculations of balance-flux distributions. Ann. Glaciol., 23, 21-27.

Drewry, D. J. 1983. Antarctica: glaciological and geophysical folio. Cambridge, University of Cambridge. Scott Polar Research Institute.

Fujita, S. and 6 others. 1999. Nature of radio-echolayering in the Antarctic ice sheet detected by a two-frequency experiment. F. Geophys. Res., 104(B6), 13,013-13,024

Hodgkins, R., M. J. Siegert and J. A. Dowdeswell. 2000. Geophysical investigations of ice-sheet internal layering and deformation in the Dome $\mathrm{C}$ region of central East Antarctica. 7. Glaciol., 46(152), 161-166.

Jacobel, R.W., A. M. Gades, D. L. Gottschling, S. M. Hodge and D. L. Wright. 1993. Interpretation of radar-detected internal layer folding in 
West Antarctic ice streams. 7. Glaciol., 39(133), 528-537.

Jacobel, R.W., T. A. Scambos, C. F. Raymond and A. M. Gades. 1996. Changes in the configuration of ice stream flow from the West Antarctic ice sheet. F. Geophys. Res., 101 (B3), 5499-5504.

Jacobel, R.W., T. A. Scambos, N. A. Nereson and C. F. Raymond. 2000. Changes in the margin of Ice Stream C, Antarctica. F. Glaciol., 46(152), $102-110$.

Jezek, K. C. and RAMP Product Team. 2002. RAMP AMM-1 SAR image mosaic of Antarctica. Fairbanks, AK, Alaska SAR Facility, in association with the National Snow and Ice Data Center, Boulder, CO.

Joughin, I. and 7 others. 1999. Tributaries of West Antarctic ice streams revealed by RADARSAT interferometry. Science, 286(5438), 283-286.

McIntyre, N. F. 1985. The dynamics of ice-sheet outlets. F. Glaciol., 31(108), 99-107.

Plewes, L. A. and B. Hubbard. 2001. A review of the use of radio-echo sounding in glaciology. Prog. Phys. Geogr., 25(2), 203-236.
Price, S.F. 1998. Studies in the catchment and onset regions of Ice Stream B, West Antarctica. (M.Sc. thesis, Ohio State University.)

Robin, G. de Q. and D. H. M. Millar. 1982. Flow of ice sheets in the vicinity of subglacial peaks. Ann. Glaciol., 3, 290-294.

Robin, G. de O., D. J. Drewry and D. T. Meldrum. 1977. International studies of ice sheet and bedrock. Philos. Trans. R. Soc. London, Ser. B, 279(963), 185-196.

Siegert, M. J. 1999. On the origin, nature and uses of Antarctic ice-sheet radio-echo layering. Prog. Phys. Geogr., 23(2), 159-179.

Siegert, M. J. and S. Fujita. 2001. Internal ice-sheet radar layer profiles and their relation to reflection mechanisms between Dome $\mathrm{C}$ and the Transantarctic mountains. F. Glaciol., 47(157), 205-212.

Vaughan, D. G., J. L. Bamber, M. B. Giovinetto, J. Russell and A. P. R Cooper. 1999. Reassessment of net surface mass balance in Antarctica. 7. Climate, 12(4), 933-946.

Whillans, I. M., J. Bolzan and S. Shabtaie. 1987. Velocity of Ice Streams B and C, Antarctica. 7. Geophys. Res., 92(B9), 8895-8902. 